\title{
8
}

\section{Stormwater Quality Modeling of Cross Israel Highway Runoff}

\section{Roger C. Sutherland, Gary R. Minton and Uri Marinov.}

The Hayarkon Springs Well Field is the major source of potable water for metropolitan Tel Aviv, Israel, supplying approximately $40 \%$ of the potable water in the nation. Concern for the potential contamination of the well field from runoff from the newly constructed Cross Israel Highway (CIH) resulted in the consideration of pavement cleaning to reduce the pollutant loading in the 2.4 kilometer section of the $\mathrm{CIH}$ that drained to the vicinity of the well field. The SIMplified Particulate Transport Model (SIMPTM) was used to evaluate the potential stormwater effects and the benefits of cleaning on stormwater quality.

The high efficiency cleaning method that was used on the highway is called "captive hydrology". This cleaning technology, which is quite popular in the United Kingdom and Western Europe, involves a single vehicle that contains several high speed rotating jets that pressure wash the pavement and immediately recover and safely contain the resulting runoff and mobilized particulate material through the use of a powerful vacuum and large dirty water holding tank. Newer versions of this technology have the ability to recycle the water within the machine so the truck's cleaning time can be maximized since frequent stops to take on clean water or dispose of dirty water are not needed.

In a classic paired basin study design, one side of the highway was periodically cleaned throughout the monitored wet weather season while the

Sutherland, R., G.R. Minton and U. Marinov. 2006. "Stormwater Quality Modeling of Cross Israel Highway Runoff." Journal of Water Management Modeling R225-08. doi: 10.14796/JWMM.R225-08.

(C) CHI 2006 www.chijournal.org ISSN: 2292-6062 (Formerly in Intelligent Modeling of Urban Water Systems. ISBN: 0-9736716-2-9) 
other side was not cleaned. Runoff from both traditional and partially porous pavements was monitored and evaluated. This chapter will provide an overview of the project and focus on the modeling process and its results.

\subsection{Introduction}

In the spring of 2000, several parties including environmental groups and biologists raised a concern that runoff from this section of the Cross Israel Highway $(\mathrm{CIH})$ will impact the groundwater quality of the Hayarkon Springs. They petitioned the Supreme Court of Israel to issue an interim injunction against the continuation of the project until the issue of water contamination is resolved. The petitioners contended that runoff from the $\mathrm{CIH}$, including toxic material spilled from traffic accidents, may pollute the underground water resources of the Hayarkon Springs.

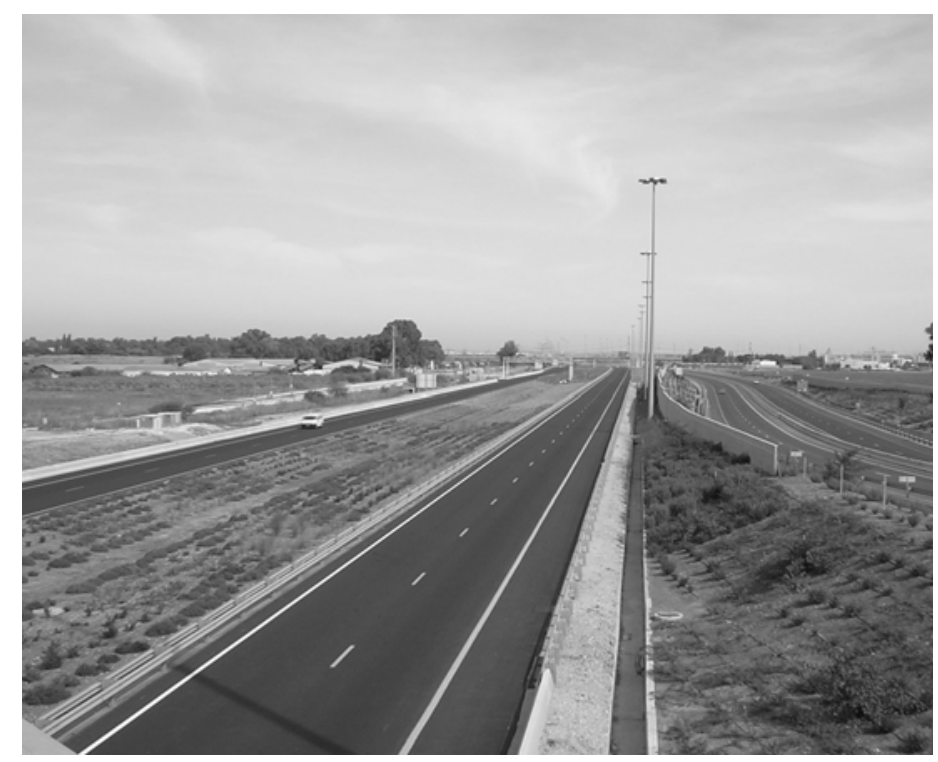

Figure 8.1 Looking north from Highway 483 overpass.

The $2.4 \mathrm{~km}$ Rosh Ha'ayin segment of the CIH (see Figure 8.1) drains to the Einat and Rosh Ha'ayin Channels. These two channels flow northwesterly and westerly respectively from the vicinity of the CIH. The 
Rosh Ha'ayin Channel merges with the Einat Channel immediately adjacent to and north of Highway 483 some $0.6 \mathrm{~km}$ downstream of the $\mathrm{CIH}$. Immediately downstream from this confluence, the Einat Channel then flows past and adjacent to the well fields of the Hayarkon Springs then it continues on to the Hyarkon River.

Early actions taken by the court led to the appointment of a group of decision-makers, called the Accompanying Team (AT). The responsibility of the AT was to develop an action plan addressing the concerns that had been raised and to oversee the implementation of the plan. The AT plan of action for the Rosh Ha'ayin segment has been referred to as the "Integrated Solution." Actions related to the water quality concerns include:

- Design, construction and operation of spill containment facilities that will capture and contain any toxic spills that could occur along the Rosh Ha'ayin segment that drains to the vicinity of the Hayarkon Springs.

- Design and implementation of a monitoring plan that obtains the data needed to eventually address the various concerns of the Accompanying Team.

- Conduct a stormwater modeling study that: characterizes the stormwater runoff from the Rosh Ha'ayin segment; determines the specific pollutant reductions associated with roadway cleanings; and provides a recommendation on the type and cleaning frequency of the most appropriate highway cleaning practice, if needed.

The Supreme Court ruled in November 2001 that the construction of the $\mathrm{CIH}$ will not be halted and the "Integrated Solution" will be implemented immediately. Anticipating this decision, the Derech Eretz Construction Joint Venture (CJV) completed the design of the required spill containment facilities that were constructed before the $\mathrm{CIH}$ opened to traffic in the fall of 2002. The ten containment facilities (see Figure 8.2) each have a control gate that remains closed at all times to contain potential spills. The facilities are designed to contain a total spill from the largest tanker truck known to transport hazardous liquids in Israel along with the estimated runoff volume from a two-year one-hour rainfall event. Once a rainfall event has ended and the operations personnel confirm that no spill occurred, the gates are automatically opened (from a control center that monitors them continuously) and the captured runoff volume is released. These containments demonstrate CIHC's commitment to clean water and their understanding of the devastating impact such a rare occurrence like a hazardous waste spill could have on the nation's water supply. 
In November 2001, Pacific Water Resources, Inc. (PWR), in association with Planning Resources Associates (RPA), was selected by Cross Israel Highway Company, Ltd. (CIHC) to conduct a study of the stormwater quality from the Rosh Ha'ayin segment and address the concerns of the Accompanying Team.

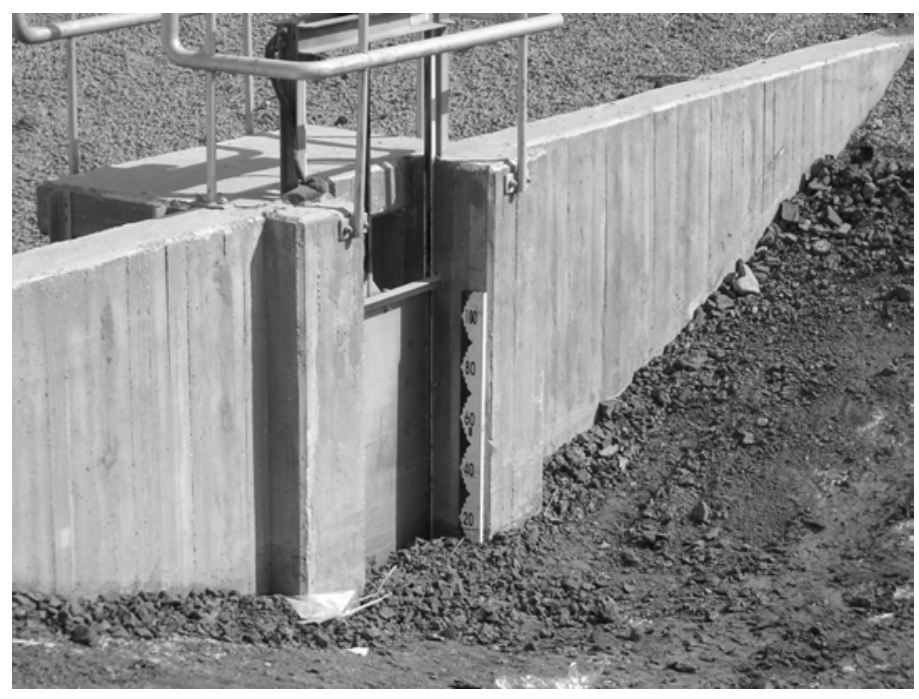

Figure 8.2 Dam and control gate for containment G2-R along northbound lanes.

\subsection{Project Goals, Objectives and Phases}

The overall study goals were to determine if cleaning actions are needed and to develop a management plan to mitigate, if necessary, the potential water quality impacts associated with stormwater from the Rosh Ha'ayin segment of the CIH. To meet these goals the following objectives of the study were identified during the preparation of the Monitoring Plan:

1. characterize the quality of the stormwater; and

2. evaluate the effect of pavement cleaning on the quality of the stormwater runoff.

A Phased approach was used by the study. Phase I involved the collection and review of basic information regarding the design of the highway and the rainfall characteristics near the Rosh Ha'ayin segment. The 
study's principal investigators traveled to Israel in January 2002 to meet with CIHC, CJV, Uri Marinov (a consultant to CIHC and former Director of the Ministry of the Environment), and the AT to discuss the stormwater study and the design of the monitoring plan. Phase I ended with the development of the Monitoring Plan dated October 2002.

Phase II involved the implementation of the monitoring plan and the interpretation of data gathered between October 2002 and July 2003 at locations along the Rosh Ha'ayin segment. The monitoring program and the interpretations of the collected data were presented in a draft monitoring report in September 2003, which, after a subsequent visit and discussion with the AT, was finalized and delivered to CIHC in May 2004.

Phase III involved the use of a stormwater quality simulation program called SIMPTM needed to simulate the pollutant accumulation and washoff by rainfall under the existing condition of low traffic volume that occurred during the summer of 2003 and the future conditions where the ultimate volume will increase to an estimated 100,000 vehicles per day. The model was calibrated to best reproduce the data collected in Phase II and to simulate the pollutant reduction benefits associated with various types of roadway cleaning practices.

Phase IV was the final documentation of Phase III modeling efforts and the recommended management program. The August 2004 report addressed both the study objectives listed above. The first objective was initially addressed in the Phase II Monitoring Report. Key to the analysis was the SIMPTM model (Sutherland and Jelen, 1998). It was used to estimate storm-by-storm and thereby annual washoff loadings of key pollutants with and without pavement cleaning. Much of the data collected in Phase II was designed for the calibration of the model. The results of the model calibration and the modeling analysis are briefly presented in this chapter.

\subsection{The Rosh Ha'ayin Segment of the $\mathrm{ClH}$}

As stated previously, the Rosh Ha'ayin segment of the CIH is close to Hayarkon Springs. It is located in the eastern fringe of the metropolitan area of Tel Aviv, as shown in Figure 8.3. It consists of two southbound and two northbound lanes, which are separated. Most of the Rosh Ha'ayin segment is on fill. New Jersey barriers are situated along the perimeter of the fill areas, to keep sediments on the highway. Water drains from, or though in the case of porous pavements, to small (i.e. $30 \mathrm{~cm}$ wide) drainage collection 
channels or gutters located at the edge of the pavement adjacent to the New Jersey barriers. At approximately every $75 \mathrm{~m}$, the water is discharged down a paved portion of the highway slope to a channel that transports the water to a containment basin. As stated previously, the purpose of the containment basin is to retain hazardous spills along with stormwater runoff up to the estimated runoff volume for a 2 y or $50 \%$ probability event.

The Rosh Ha'ayin segment of the CIH has both traditional and porous pavements. The porous pavement is not fully porous. Rather, only the final lift of approximately $40 \mathrm{~mm}$ is porous. Its purpose is to reduce noise and wet weather skid potential. The porous lift, however, creates a $30 \mathrm{~cm}$ wide channel that concentrates the runoff that does occur to an area immediately adjacent to and along the New Jersey barriers. To reduce costs, the porous pavement is used only in the immediate vicinity of populated areas. Hence, the monitoring was structured to ascertain possible differences in road dirt accumulations, washoff loadings, speciation of pollutants, and effects of cleaning practices between the two types of pavement. During the period of monitoring, the northbound shoulders were periodically cleaned with the captive hydrology cleaner.

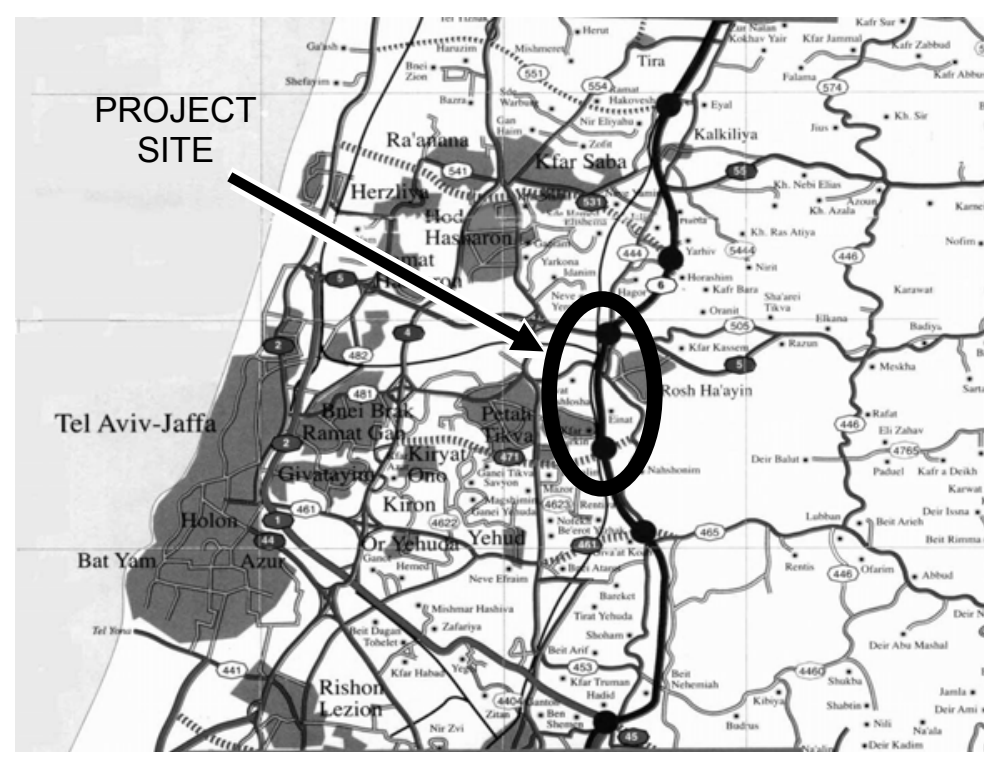

Figure 8.3 The Rosh Ha'ayin segment of the $\mathrm{ClH}$. 


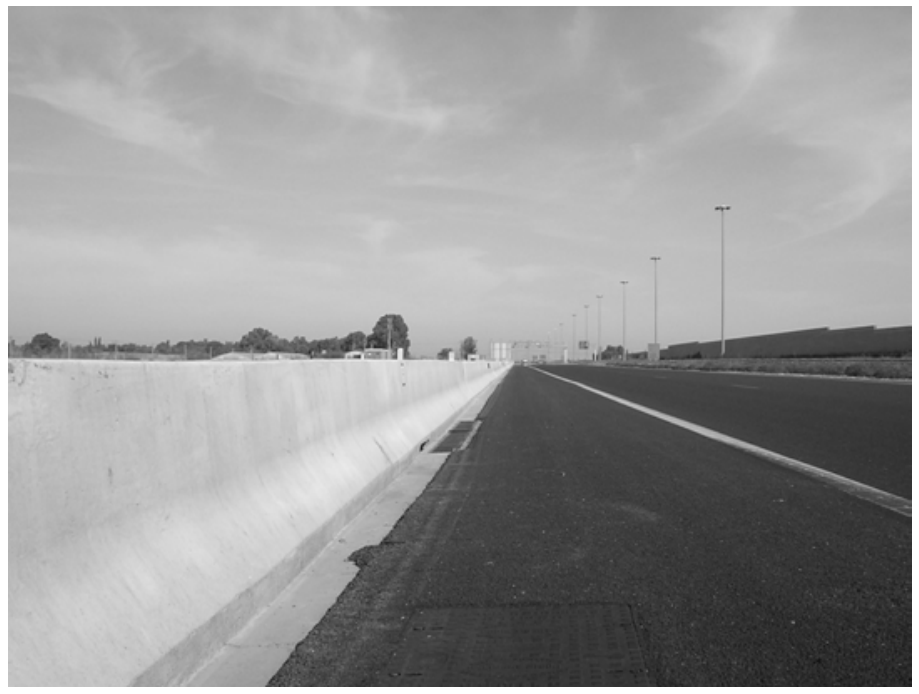

Figure 8.4 Looking north along southbound porous pavement section near pavement sampler SP20.

\subsection{Monitoring Study}

The types of data collected during the monitoring study (Phase II) were the following:

- quality of stormwater from the $\mathrm{CIH}$ pavements and containment basins;

- quality of stormwater in the Rosh Ha'ayin and Einat Channels;

- accumulation rates of road dirt on the $\mathrm{CIH}$;

- accumulation rates of road dirt on two existing highways with high traffic volumes;

- physical and chemical characteristics of the road dirt on the three highways; and

- pick-up performance of the Netivey Hamifratz (NH) pavement cleaner.

Eleven storms were monitored during the wet season of 2002-2003. Approximately 200 individual samples were taken and analyzed. The stormwater samples collected during Phase II were analyzed for 35 analytes, 
identified by the Accompanying Team as possible pollutants of interest. The examination of data, presented in the Phase II report (May 2004), found that the concentrations of pollutants in the stormwater from the $\mathrm{CIH}$ are typical of that observed of highways in other countries for the current traffic conditions.

\subsection{Pollutants of Interest}

Inherent to water quality planning is the establishment of a list of the pollutants of interest. Traditionally this is accomplished by the use of water quality standards. Water quality standards are generally specified as the maximum concentration a given pollutant can reach before a beneficial use is assumed to be impaired. Beneficial uses include human consumption, agricultural irrigation, industrial water supply, recreation like swimming, and aquatic species protection. Human consumption is regulated by drinking water standards. Other beneficial uses are commonly regulated by receiving water standards.

The AT identified 35 analytes as possible pollutants of interest. Of these, the monitoring of stormwater from the Rosh Ha'ayin segment found that 31 analytes exceeded the detection limit in at least $10 \%$ of the samples of stormwater.

For the purposes of modeling the number of potential pollutants was further reduced to seven for two reasons. The first reason was to focus on those analytes that appear, based on the Phase II results, to exceed either the Israel Drinking Water Standards or the draft Kishon River Standards. (The draft standards were prepared by the Israeli Ministry of Environment but have not been approved.) The second reason was to make the modeling task manageable.

The modeling analysis using SIMPTM focused on these pollutants:

- Total Suspended Solids (TSS),

- Total Chromium (TCr),

- Total Copper $(\mathrm{TCu})$

- Total Lead $(\mathrm{TPb})$,

- Total Zinc (TZn),

- Total Nitrogen (TN), and

- Total Phosphorus (TP).

TSS was selected because it is the primary pollutant simulated by SIMPTM. Other pollutants are related to this simulation. The four metals in 
the above list were selected based on the review of the stormwater data collected during Phase II. This review suggested that exceedances of either the drinking water or draft receiving water standards may occur at a traffic volume of 100,000 vehicles per day. However, the monitoring data indicated that at the low traffic volume during the monitoring period, of about 10,000 vehicles, only the chromium standard was exceeded. Both the chromium and lead concentrations exceeded the draft Kishon River Standards. Nitrogen and phosphorus were included as they are nutrients.

Considering that the concern regarding stormwater from the Rosh Ha'ayin segment is related to the potential contamination of the drinking water supply of the Hayarkon Springs, it is most appropriate that the Accompanying Team focus on the Israel Drinking Water Standards. However, the draft Kishon River receiving water standards have also been proposed although they may not be valid for either the Einat or Rosh Ha'ayin Channels that receive stormwater from the CIH. Nonetheless, the modeling analysis considered both sets of standards.

\subsection{Modeling Highway Stormwater Pollution}

Modeling provides an opportunity to simulate the site-specific pollutant accumulation and washoff processes that occur over time, including the removal of accumulated pollutants by various cleaning practices. With modeling a relatively limited set of monitoring data can be used to calibrate the model. The calibrated model is then used to simulate the accumulation and washoff behaviors over a much longer time frame and for conditions that do not currently exist, in particular future traffic volumes.

Highway stormwater pollution results from the accumulation and washoff of contaminated material on pavement surfaces. The sources of these road dirt accumulations are varied and research has shown that their magnitude is directly correlated with the traffic volume the highway experiences. A USEPA study entitled Contributions of Urban Roadway Usage to Water Pollution (Shaheen, 1975) examined the variables that affect the deposition of highway surface contaminants by collecting accumulated sediments from nine sites located throughout the Washington, D.C. and Baltimore, Maryland areas. The Average Daily Traffic (ADT) of the monitored sites ranged from zero (a new unopened highway) to 109,000 vehicles per day. The study found strong relationships between the accumulation of highway surface contaminants and the observed traffic 
volume for the following pollutants: total solids, volatile solids, biochemical and chemical oxygen demand (BOD and COD, respectively), grease, total phosphate, nitrates, nitrites, Kjeldahl nitrogen, chloride, petroleum, asbestos, rubber, lead, chromium, copper, nickel and zinc.

The ability of stormwater runoff to transport sediment and sedimentborne pollutants depends upon many factors. These include the amount of the accumulated material and its particle size distribution, the pollutant chemistry or road dirt quality, the intensity and duration of storms, and the physical characteristics of the pavement and roadway such as curbing and landscaping.

The simulation model must have the capability to create a continuous simulation that spans several decades and estimate the storm-by-storm runoff volumes, pollutant concentrations and mass loadings for the various pollutants of interest that would have been discharged from the $\mathrm{CIH}$ under an ultimate traffic volume of approximately 100,000 vehicles per day. This long term simulation creates a large population of storm pollutant concentrations that can be analyzed to determine what percentage of those concentrations for a critical pollutant, like total chromium for example, actually exceeded a given water quality standard. The model must also be able to evaluate the pollutant reduction benefits associated with various types and frequencies of highway cleaning practices. The pollution reduction benefits should be measured as a mass reduction in annual pollutant washoff or a decrease in the percentage of storms where a given water quality standard was exceeded.

As stated previously, the SIMplified Particulate Transport Model (SIMPTM) was selected for use on this project. SIMPTM (Sutherland and Jelen, 1998) can simulate the accumulation, washoff and removal processes that occur on streets and highways. It also has the ability to simulate the pollution reduction benefits associated with various cleaning operations. The benefit of SIMPTM is that it explicitly models the accumulation and washoff of pollutants, unlike other models like the USEPA SWMM model that uses simplified exponential functions (Sutherland and Jelen, 2002).

Most modeling techniques simplistically determine the pollutant loading by multiplying the rainfall runoff of each event times an assumed average pollutant concentration, invariable from storm to storm. This approach does not provide satisfactory estimates of storm-by-storm concentrations. Additionally, the approach tends to significantly overstate the total pollutant loading. In contrast, the SIMPTM model explicitly simulates the physical processes of stormwater runoff to transport accumulated road dirt and attached pollutants for each storm. The model thereby provides the most 
accurate simulation of the amount of material washed off during each storm, with an accounting of what remains on the pavement for the next storm. This washoff computation is repeated every six minutes throughout each historic runoff event. A running summation of these incremental pollutant mass washoffs from each timestep provides the estimated pollutant loading for the storm event.

The overall goals for the modeling of stormwater quality from the Rosh Ha'ayin segment of the $\mathrm{CIH}$ are to determine (i) whether water quality standards are being exceeded once the highway's ultimate traffic is realized, (ii) how frequently these exceedances may occur, and (iii) how various cleaning practices implemented over time on the highway can reduce the frequency of the exceedances to some specified level.

\subsubsection{Modeling Tasks}

The key tasks in preparing and using the model were:

1. Obtain and analyze the historic rainfall record from a nearby rainfall gage to establish a simulation time period. The results of this analysis are presented in Section 8.6.2.

2. Analyze the dry weather road dirt data collected during the summer of 2003 to obtain the accumulation curves for both low and high traffic volumes on both traditional and porous asphalt pavements. Low traffic volumes were those that occurred on the CIH during the May-July 2003 monitoring period. High traffic volumes were those that occurred on Highways 1 and 4 during the same period.

3. Analyze the road dirt data to establish the particle size distributions and the chemical qualities of the pollutants of interest to be used in the model calibration in Task 4 .

4. Using the accumulation curves for low traffic volumes from Task 2 and recent rainfall data from the nearby gage, calibrate the model to best represent the $\mathrm{CIH}$ wet weather road dirt accumulation and pollutant concentration data that was observed on both traditional and porous asphalt pavements from October 2002 through April 2003, the wet weather monitoring period.

5. Using the historic rainfall record from Task 1 and the calibrated model from Task 4, simulate the historic longterm storm-by-storm runoff volumes, pollutant concentrations and mass loadings for low traffic volumes. 
6. Change the accumulation curves to those that reflect high traffic volumes from Task 2 and re-run the calibrated model from Task 4.

7. Analyze the simulated populations of pollutant concentrations and mass loadings from both Task 5 and Task 6 to obtain summary statistics and identify the frequency of water quality standard exceedances.

8. Use the model from Task 6 to evaluate the pollutant reduction benefits associated with various types and frequencies of street cleaning.

9. Use the model to estimate the pollutant mass load reductions associated with the alternative cleaning practices on both traditional and porous asphalt pavements under both low and high volume traffic conditions.

\subsubsection{Analysis of the Historic Rainfall Record}

The SIMPTM modeling package includes a separate program called RAINEV. It is a rainfall analyzer used to evaluate the characteristics of a historic rainfall record. The program divides hourly precipitation records into significant rainfall events and calculates the starting date, duration, depth, time since the last event ended, average intensity, and maximum hourly intensity for all recorded events. The precipitation analysis is a required input file used in the SIMPTM water quality modeling.

For the CIH Stormwater Quality Study, a long-term hourly rainfall record from a station located at Kibbutz Einat immediately east of The Rosh Ha'ayin segment was used. This station provided a $57 \mathrm{y}$ period of rainfall from January 1, 1938 through December 31, 1994 for the model simulations. A 57 y record of rainfall was used for the following reason. For any one future year its particular sequence of storms and storm depths is unknown. Using the historic rainfall record, it is assumed that any future year will mimic a previous historic year of record: that is the future will occur as the past, but the particular year in which this occurs is random and unknown. By simulating loadings based on the historic rainfall record the potential variation in loadings and concentrations is defined to the extent possible. The validity of this approach is recognized when considering that the rainfall during the monitoring period of October 2002 through April 2003 was abnormally and unusually wet. The rainfall was approximately $126 \%$ of normal. If only this one time period had been used for simulation, the 
loadings and concentrations would have been overstated. An analysis of the rainfall during the monitoring period is presented in Section 8.7.2. The monthly averages for rainfall duration and depth found at this location along with the average event for each month is presented in Table 8.1.

The average number of events is based on all rainfall events recorded with at least $1 \mathrm{~mm}$ of rainfall in $1 \mathrm{~h}$, or $1.7 \mathrm{~mm}$ in $3 \mathrm{~h}$, or $2.5 \mathrm{~mm}$ in $6 \mathrm{~h}$. The ending of a rainfall event was defined as a period of three hours where no rainfall was recorded.

Data in Table 8.1 shows that no rainfall occurs during the months of June, July and August and very little has been recorded during the months of May and September. The wet weather season is from October through April, where $99.5 \%$ of the annual rainfall occurs.

Table 8.1 Average rainfall characteristics at Kibbutz Einat.

\begin{tabular}{cccc|ccc}
\hline \multicolumn{3}{c|}{ Monthly Averages } & \multicolumn{3}{c}{ Event Averages } \\
\hline Month & $\begin{array}{c}\text { Number } \\
\text { of Events }\end{array}$ & $\begin{array}{c}\text { Duration } \\
(\mathrm{hrs})\end{array}$ & $\begin{array}{c}\text { Depth } \\
(\mathrm{mm})\end{array}$ & $\begin{array}{c}\text { Depth } \\
(\mathrm{mm})\end{array}$ & $\begin{array}{c}\text { Duration } \\
(\mathrm{hrs})\end{array}$ & $\begin{array}{c}\text { Intensity } \\
(\mathrm{mm} / \mathrm{hr})\end{array}$ \\
\hline January & 8.5 & 31.6 & 78.65 & 9.23 & 3.1 & 2.11 \\
February & 7.7 & 24.8 & 56.54 & 7.31 & 2.8 & 1.89 \\
March & 5.8 & 15.8 & 33.37 & 5.78 & 2.2 & 1.71 \\
April & 1.5 & 3.8 & 9.25 & 6.28 & 0.9 & 1.09 \\
May & 0.2 & 0.5 & 1.19 & 5.65 & 0.2 & 0.31 \\
June & 0.0 & 0.0 & 0.00 & 0.00 & 0.0 & 0.00 \\
July & 0.0 & 0.0 & 0.00 & 0.00 & 0.0 & 0.00 \\
August & 0.0 & 0.0 & 0.00 & 0.00 & 0.0 & 0.00 \\
September & $<.01$ & 0.1 & 0.28 & 7.95 & 0.0 & 0.09 \\
October & 1.2 & 2.6 & 8.43 & 7.17 & 0.7 & 1.19 \\
November & 4.5 & 14.3 & 44.81 & 9.94 & 2.0 & 2.63 \\
December & 6.1 & 22.5 & 65.57 & 10.80 & 2.5 & 2.14 \\
\hline Average & 35.5 & 113.1 & 298.10 & 8.40 & 3.3 & 2.57 \\
Year & & & & & & \\
\hline
\end{tabular}

2037 events modeled, 1938 - 1994 


\subsection{Model Calibration}

Task 4 of the modeling process is important since proper calibration of the SIMPTM model is key to providing satisfactory simulations. Calibration is derived from the road dirt accumulation and pollutant concentration data observed on both traditional and porous asphalt pavements from October 2002 through April 2003.

The timing of the rainfall events, samplings and cleanings on the $\mathrm{CIH}$ during the monitoring period is presented later. On October 4, 2002, which was approximately two weeks before the first rain of the season, a two meter wide strip on both the southbound and northbound shoulders immediately adjacent to the New Jersey barrier or curb was first cleaned by the Netivey Hamifratz cleaner (see Figure 8.5), followed immediately by manual cleaning using an attachment to a vacuum sweeper (see Figure 8.6) to ensure the gutter next to the barrier was clean. Also, as stated previously, the $40 \mathrm{~mm}$ porous lift creates a $30 \mathrm{~cm}$ wide channel that must be cleaned since it can easily trap accumulated road dirt.

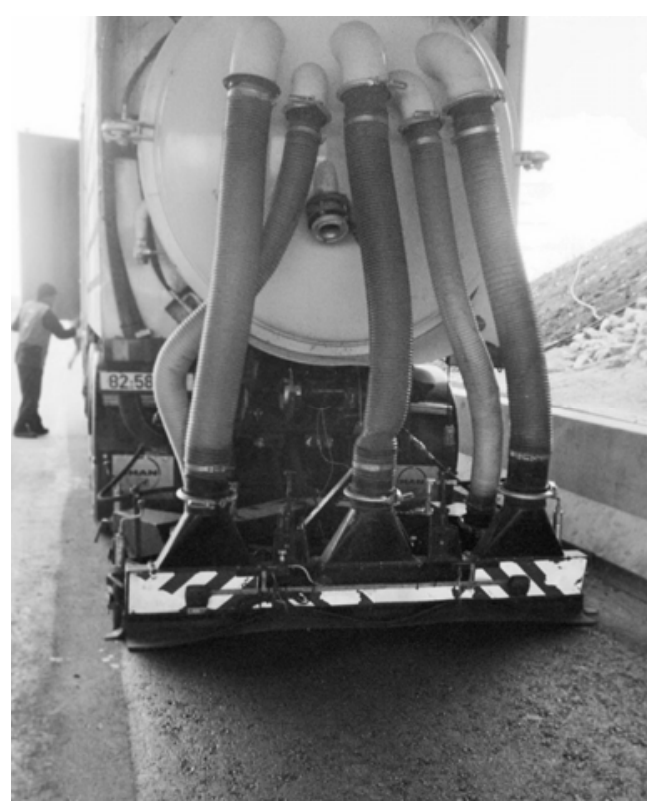

Figure 8.5 Netivey Hamifratz cleaner. 


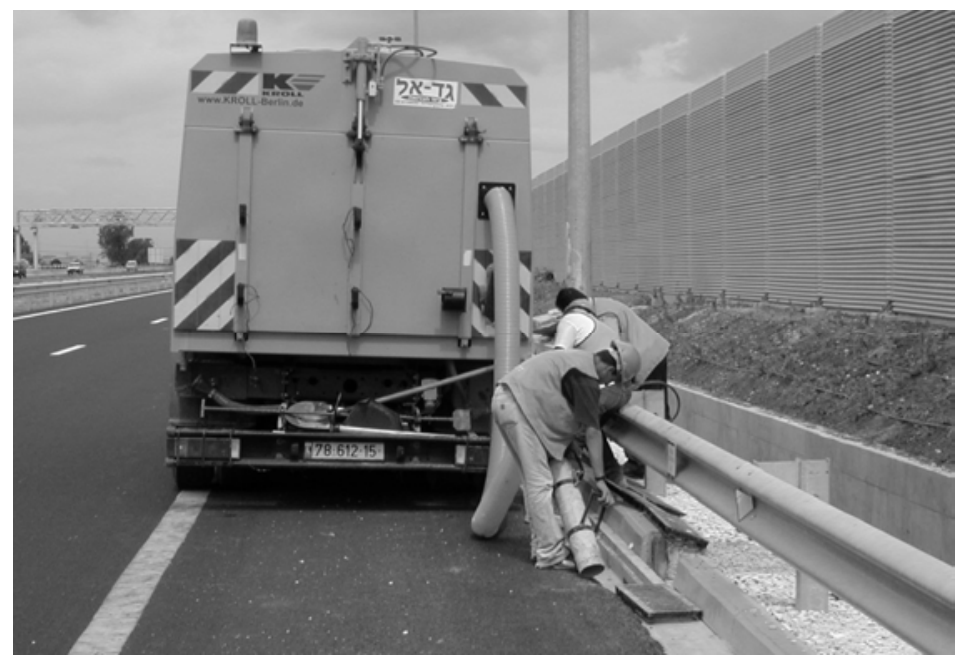

Figure 8.6 Vacuum cleaning of gutter.

This cleaning procedure was repeated on January 27, 2003 and March 28, 2003 for the northbound shoulder only. During the monitoring period, eleven runoff events were sampled from October 15, 2002 through April 27, 2003. However, the analysis of rainfall data from nearby Kibbutz Einat shows that approximately 78 separate events occurred during this period in which it rained on 51 days. The depths of those events are shown in Figure 8.7.

As Figure 8.7 shows, road dirt sampling occurred nine times between November 14, 2002 and March 30, 2003. Both traditional and porous asphalt pavements were sampled. However, the northbound pavements were only sampled five times from January 13, 2003 to March 16, 2003 whereas the southbound pavements were sampled all nine times. Road dirt accumulations along the northbound pavements were heavier throughout the fall and early winter of 2002 due to heavily loaded untarped trucks emanating from a rock quarry in Rosh Ha'ayin spilling sediments along that shoulder. This additional sediment source terminated in January 2003 when CIHC began charging a toll for the use of the highway. As a result, the trucks discontinued their use of the $\mathrm{CIH}$. Because of this additional accumulation on the northbound shoulder, the model calibration focused on the data collected along the southbound shoulder only. The objective of the model calibration was to closely match the road dirt accumulations and pollutant washoffs observed on the southbound shoulder October 2002 through March 2003. 


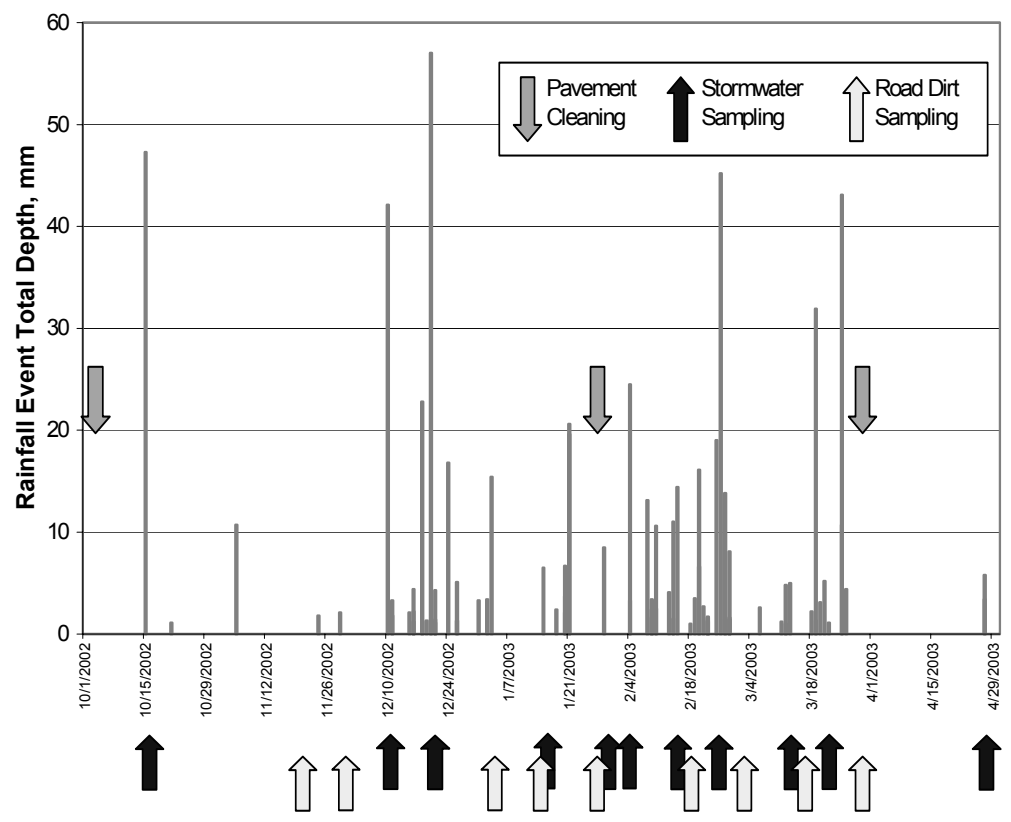

Figure 8.7 Timing of rainfall events, samplings and cleanings on the Cross Israel Highway.

\subsubsection{Model Calibration Steps}

The calibration itself involved three steps, each briefly described as follows:

1. Working with the two road dirt accumulation curves for low volume traffic and with the rainfall during the monitoring period, the accumulation parameters of the model are adjusted to best reproduce the $\mathrm{CIH}$ wet weather road dirt accumulations observed on both the southbound traditional and porous asphalt pavements (see Figure 8.8).

2. In an iterative process that uses the results from calibration Step 1, the washoff parameters of the model are adjusted to best reproduce the total suspended solids concentrations observed in the discharges from both the 
southbound traditional and porous asphalt pavements (see Figure 8.9).

3. Using the final calibrated model for TSS, the average pollutant road dirt qualities that were observed for the fine, medium and coarse fraction of the accumulated road dirt were adjusted to best reproduce the variation found in the paired concentrations between the pollutant of interest and TSS observed in the discharges from both the southbound traditional and porous asphalt pavements (see Figure 8.10).

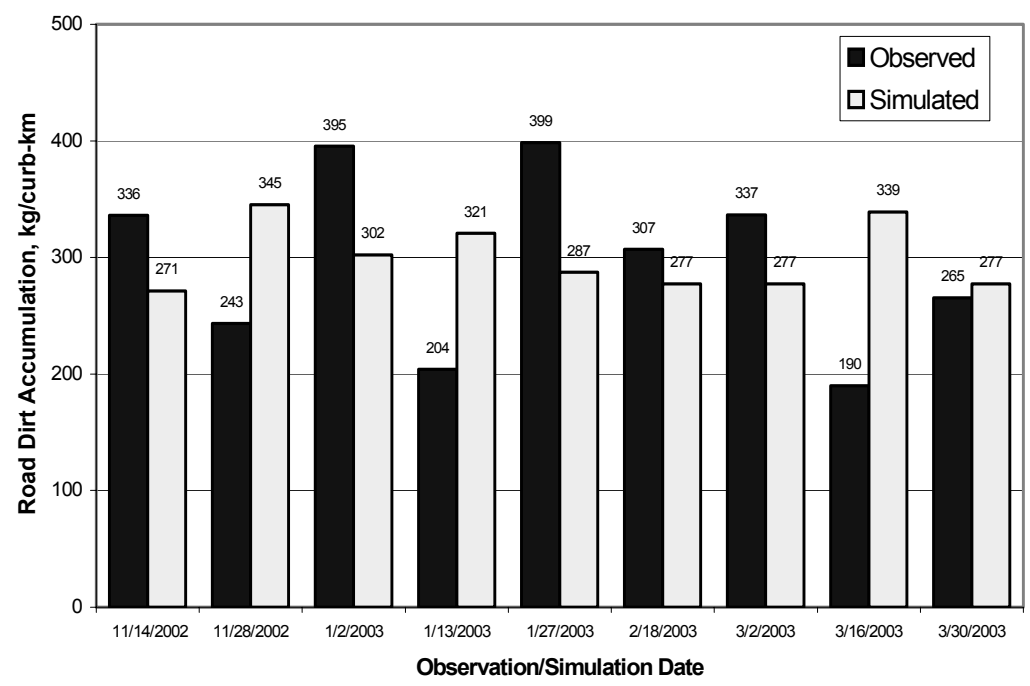

Figure 8.8 Simulated versus observed road dirt accumulations on porous $\mathrm{ClH}$ pavements.

The calibration to the porous pavement accumulations shown in Figure 8.8 is quite good. The observed accumulations are greater than the simulated in five of the nine samplings, whereas the reverse is true in the remaining four samplings. This is the behavior of a good calibration. It should be noted that the simulated coefficients of variation (COVs) for both traditional and porous pavement were always less than those observed. This is generally the case for most models since the variation of what is observed, like road dirt accumulation, is usually much greater than what a model simulates. 


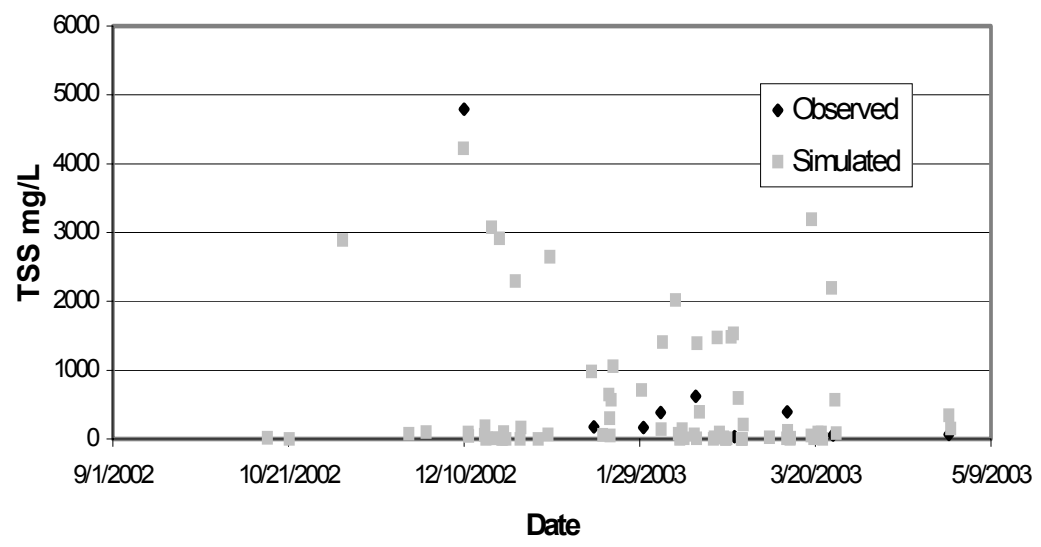

Figure 8.9 Simulated versus observed TSS concentrations from traditional $\mathrm{ClH}$ pavements.

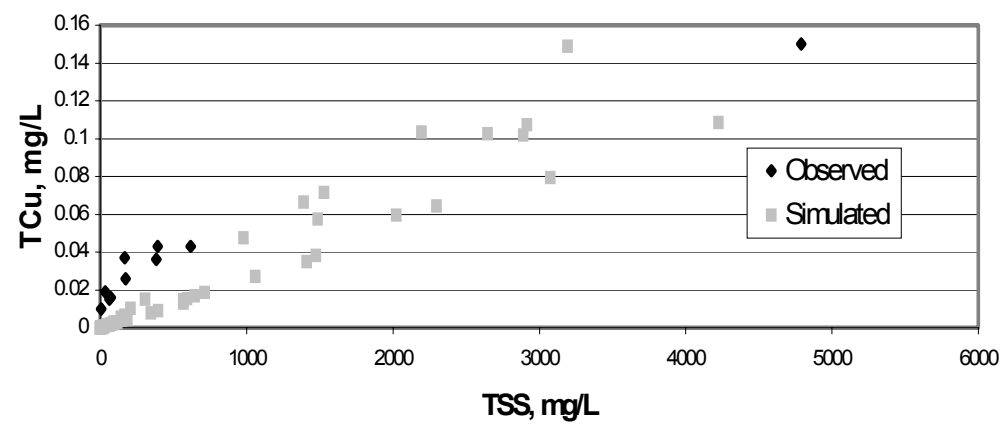

Figure 8.10 Simulated versus observed paired TCu and TSS concentrations from traditional $\mathrm{ClH}$ pavements.

\subsubsection{Rainfall Characteristics During the Monitoring Period}

Rainfall depth data from the Kibbutz Einat gage was obtained for October 2002 through April 2003. Analysis shows the monitoring period was very wet compared to the long-term average rainfall characteristics in Table 8.1. Approximately 78 events totaling some $670 \mathrm{~mm}$ occurred during the monitoring period, which is $126 \%$ more depth than the long term average of $297 \mathrm{~mm}$ occurring in an average of 35.3 events. Table 8.2 shows a monthly 
comparison of the rainfall recorded during the monitoring period to the longterm averages.

Table 8.2 Comparison of rainfall characteristics recorded during the monitoring period to the long-term averages.

\begin{tabular}{ccccccc}
\hline & \multicolumn{3}{c}{ Number of Events } & \multicolumn{3}{c}{ Rainfall Depth } \\
\cline { 2 - 7 } Month & $\begin{array}{c}\text { Monitoring } \\
\text { Period }\end{array}$ & $\begin{array}{c}\text { Historic } \\
\text { Average }\end{array}$ & $\begin{array}{c}\% \\
\text { Difference }\end{array}$ & $\begin{array}{c}\text { Monitoring } \\
\text { Period }\end{array}$ & $\begin{array}{c}\text { Historic } \\
\text { Average }\end{array}$ & $\begin{array}{c}\% \\
\text { Difference }\end{array}$ \\
\hline October & 2 & 1.2 & $+67 \%$ & 48.4 & 8.4 & $+476 \%$ \\
November & 3 & 4.5 & $+50 \%$ & 14.6 & 44.8 & $-67 \%$ \\
December & 19 & 6.1 & $+211 \%$ & 174.1 & 65.6 & $+165 \%$ \\
January & 10 & 8.5 & $+18 \%$ & 88.6 & 78.7 & $+13 \%$ \\
February & 28 & 7.7 & $+264 \%$ & 218.6 & 56.5 & $+287 \%$ \\
March & 14 & 5.8 & $+141 \%$ & 117.6 & 33.4 & $+244 \%$ \\
April & 2 & 1.5 & $+33 \%$ & 9.2 & 9.3 & $-1 \%$ \\
Totals & 78 & 35.3 & $+121 \%$ & 671.1 & 296.7 & $+126 \%$ \\
\hline
\end{tabular}

The amount and intensity of rainfall that fell in the months of October, December, February and March was extremely high compared to the longterm average. As a result, it is possible that the pollutant concentrations and/or loadings observed during several of the sampled events during these months were higher than expected during an average year.

\subsection{Model Results}

The calibrated SIMPTM model was used to simulate the runoff volume, pollutant loading, and pollutant concentration for each storm through the $57 \mathrm{y}$ of rainfall data. The simulations were for discharges from both traditional and porous asphalt pavements under both low and high traffic volumes, and with and without alternative cleaning practices. As discussed in Section 8.6.2, the simulation used the $57 \mathrm{y}$ rainfall record of the Kibbutz Einat gage, from January 1, 1938 through December 31, 1994.

\subsubsection{Simulated Pollutant Loadings and Concentrations}

Pollutant loadings are the mass of a pollutant transported by stormwater from a designated area over a specified time period. The units are in kilograms per curb-kilometer $(\mathrm{kg} / \mathrm{curb}-\mathrm{km})$ for streets and highways. In 
Tasks 5 through 7 of the modeling process (see Section 8.6.1), the model was used to simulate over the historic rainfall record the storm-by-storm pollutant mass loadings and concentrations. This was done for both low and high traffic conditions with no shoulder cleaning operations. Low traffic volumes were those that occurred on the CIH during the May-July 2003 monitoring period. High traffic volumes were those that occurred on Highways 1 and 4 during the same period.

Pollutant loadings are very important as they are used to compare the magnitude of pollution originating from a source of interest like the $\mathrm{CIH}$ to that of other source areas such as agricultural lands, urban lands and other highways. Pollutant loadings can also be used to quantify the water quality benefits of alternative cleaning practices (which is discussed in Section 8.8.2) by using the SIMPTM model to estimate the reduction in the annual pollutant loadings, which will in turn reduce the loadings and concentrations of other pollutants like chromium. Although pollutant loadings are important, most scientists concerned with stormwater pollution prefer to sample and evaluate the concentrations of pollutants in stormwater since these values can be easily compared to various water quality standards like those for drinking water.

Table 8.3 presents the average annual pollutant loadings for discharges from the Rosh Ha'ayin segment's asphalt pavements over the $57 \mathrm{y}$ simulation. The table shows that a ten-fold increase in traffic volume will, depending on the pollutant, results in an average increase of $291 \%$ to $315 \%$ in annual mass loadings from the $\mathrm{CIH}$.

Table 8.3 indicates that the annual pollutant loadings increase by only a factor of approximately three although the volume of traffic increases by a factor of 10. How is this possible? There are two reasons. First, as shown in Figure 8.11, the amount of road dirt that accumulates on highways is not directly proportional to the traffic volume. For example, the accumulation found on existing high traffic highways (i.e. 100,000 vehicles per day) was only 5 times greater than that found on the $\mathrm{CIH}$, which actually had 10 times less traffic. Secondly, at higher quantities of accumulated road dirt most of the storms have insufficient intensities and volumes needed to remove all of the accumulated material. The general relationships between traffic volume and road dirt accumulation in Figure 8.11 are consistent with other studies of highways in the United States and Europe (Drapper, et al., 2000; Driscoll, et al., 1990; Hoffman, et al., 1985; Horner and Mar, 1984; Irish, et al., 1998; Kobriger, N.P., 1981; Shirley, et al., 1982; Thomson, et al., 1997; Wu, et al., 1998). 
Table 8.3 Average annual pollutant loadings ${ }^{\mathrm{a}}$ and mean concentrations $^{b}$ for the $\mathrm{ClH}$ under low $^{\mathrm{c}}$ and high ${ }^{\mathrm{d}}$ traffic volume conditions with no cleaning.

\begin{tabular}{|c|c|c|c|c|c|c|c|}
\hline \multirow[b]{2}{*}{ Pollutant } & \multicolumn{2}{|c|}{ Loadings } & \multirow[b]{2}{*}{$\begin{array}{c}\text { Percent } \\
\text { Increase }\end{array}$} & \multicolumn{2}{|c|}{ Concentrations } & \multirow{2}{*}{$\begin{array}{c}\text { Drinking } \\
\text { Standards } \\
\mathrm{Mg} / \mathrm{L}\end{array}$} & \multirow{2}{*}{$\begin{array}{c}\text { Draft } \\
\text { River } \\
\text { Standards } \\
\mathrm{Mg} / \mathrm{L}\end{array}$} \\
\hline & $\begin{array}{l}\text { Low } \\
\text { Traffic }\end{array}$ & $\begin{array}{l}\text { High } \\
\text { Traffic }\end{array}$ & & $\begin{array}{l}\text { Low } \\
\text { Traffic }\end{array}$ & $\begin{array}{c}\text { High } \\
\text { Traffic }\end{array}$ & & \\
\hline TSS & 498 & 1976 & 297 & 112 & 443 & $\mathrm{NS}^{\mathrm{e}}$ & NS \\
\hline $\mathrm{TCr}$ & .017 & .067 & 294 & .021 & .032 & 0.05 & 0.01 \\
\hline $\mathrm{TCu}$ & .012 & .048 & 300 & .018 & .026 & 1.40 & 0.05 \\
\hline $\mathrm{TPb}$ & .056 & .231 & 313 & .013 & .052 & 0.10 & 0.01 \\
\hline $\mathrm{TZn}$ & .054 & .224 & 315 & .083 & .121 & 5.00 & 1.00 \\
\hline $\mathrm{TN}$ & 1.63 & 6.37 & 291 & .365 & 1.43 & NS & NS \\
\hline TP & .301 & 1.22 & 305 & .067 & .274 & NS & NS \\
\hline
\end{tabular}

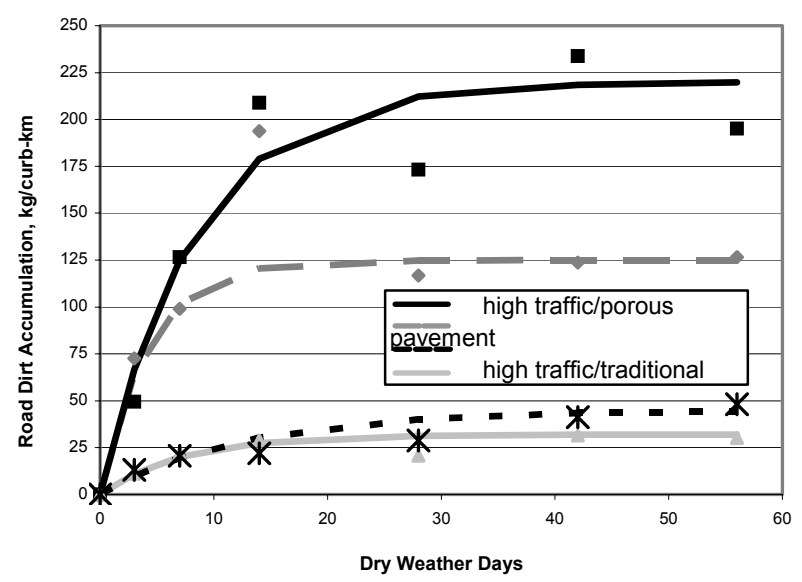

Figure 8.11 Dry weather road dirt accumulation.

The average annual loadings shown in Table 8.3 were obtained as follows. The individual mass loadings for each of the 2037 storms washed off of a representative area of the Rosh Ha'ayin segment that drains to a single spillway were summed. This total was divided by the curb-kilometers of the tributary drainage area and by the $57 \mathrm{y}$ of the simulation period. 
Figure 8.12 presents the paired TSS and chromium concentrations simulated for all of the 2037 storms over the $57 \mathrm{y}$ period. The simulations are for a traffic volume of 100,000 vehicles per day with no pavement cleaning. Figure 8.12 shows that there is a relationship between TSS concentrations and chromium concentrations, and in turn, loadings. Therefore, the strategy to reduce the concentration of chromium is to reduce the TSS loading.

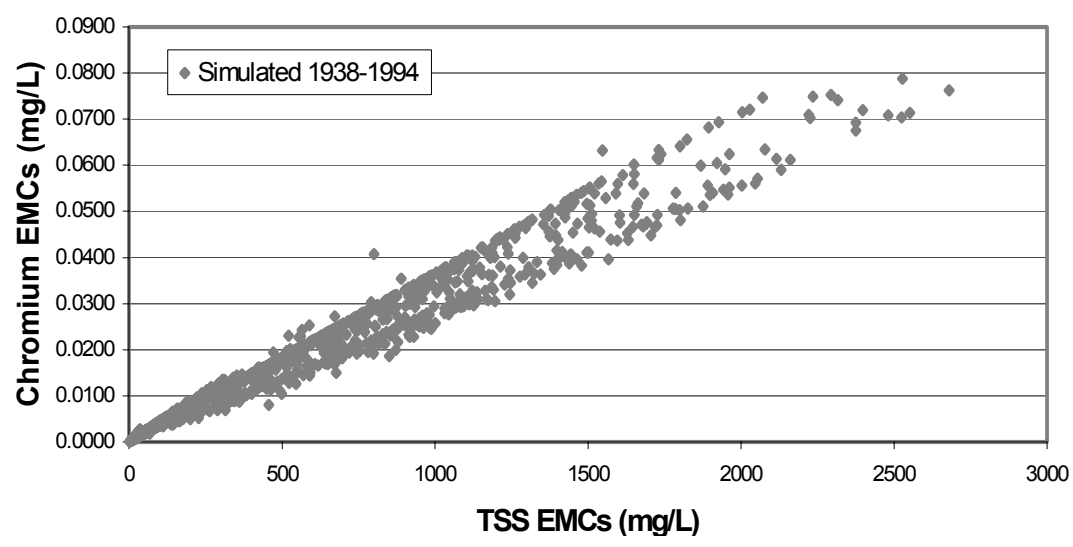

Figure 8.12 Simulated TSS and Chromium event mean concentrations from traditional $\mathrm{ClH}$ pavements with high traffic volume.

The statistical characteristics of the individual TSS and chromium concentrations for the 2037 storms are presented in Table 8.4. The chromium concentrations have been adjusted by adding a constant dissolved chromium concentration of $0.017 \mathrm{mg} / \mathrm{L}$ to each EMC (observed average value).

The statistics in Table 8.4 suggest that chromium concentrations in stormwater from the traditional pavements of the Rosh Ha'ayin segment under the projected conditions of approximately 100,000 vehicles per day will exceed the Israeli drinking water standard of $0.05 \mathrm{mg} / \mathrm{L}$ for approximately $13.3 \%$ of the storms or 271 out of 2037 storms that occurred during the $57 \mathrm{y}$ simulation period. This represents an average of about five exceedances per year. In other words, the Israeli drinking water standard for chromium will be met for $86.7 \%$ of the storms under the conditions of 100,000 vehicles per day with no pavement cleaning. 
Table 8.4 Statistical characteristics of paired TSS and chromium event mean concentrations from traditional $\mathrm{ClH}$ pavements with high traffic volume.

\begin{tabular}{|c|c|c|}
\hline \multirow[b]{2}{*}{ Statistic } & \multicolumn{2}{|c|}{ Simulated Event Mean Concentrations } \\
\hline & $\begin{array}{l}\text { Total Suspended } \\
\text { Solids (TSS) } \\
(\mathrm{mg} / \mathrm{L})\end{array}$ & $\begin{array}{l}\text { Chromium } \\
(\mathrm{mg} / \mathrm{L})\end{array}$ \\
\hline Mean (x) & 430 & 0.031 \\
\hline Median & 238 & 0.026 \\
\hline Standard Deviation (SD) & 479 & 0.015 \\
\hline $\begin{array}{l}\text { Coefficient of Variation } \\
\text { / } \cap \text { I } /\end{array}$ & 1.11 & 1.05 \\
\hline 80 Percentile & 776 & 0.042 \\
\hline 90 Percentile & 1120 & 0.054 \\
\hline 95 Percentile & 1451 & 0.064 \\
\hline
\end{tabular}

Simulations indicate that the frequency of standard exceedances for lead are similar to chromium, on the order of $13 \%$. However, this simulation does not recognize the long-term effects of the use of unleaded gas, which will diminish the concentrations of lead in stormwater. Hence, the simulations overstate the likely frequency of future exceedances. In contrast, the concentrations of copper and zinc did not exceed the drinking water standard in any of the 2037 simulated storms. With respect to the proposed Kishon River receiving water standard, exceedances for the proposed chromium standard of $0.01 \mathrm{mg} / \mathrm{L}$ would occur for $100 \%$ of the storms at 100,000 vehicles per day. The proposed Kishon River standards for the other metals were always exceeded also.

\subsubsection{Load Reductions From Cleaning Practices}

In Tasks 8 and 9 of the modeling process (see Section 8.6.1) the simulations over the historic $57 \mathrm{y}$ rainfall record were of pollutant load reductions achieved from pavement cleaning practices. The ability of a street cleaner to reduce overall pollutant washoff loads depends on several factors. First and foremost is the cleaner's innate ability to remove accumulated road dirt. Another factor is the complex environmental dynamics of road dirt accumulation between storm events and the washoff during each storm event. The SIMPTM model can accurately simulate this complicated interaction of road dirt accumulation and washoff. 
Consequently, the interaction of street cleaning throughout the simulated period is a logical extension of the model's capabilities (see Sutherland and Jelen, 1997 for more information on SIMPTM's street cleaning functions). Four street cleaning technologies were evaluated for use on the $\mathrm{CIH}$, specifically newer mechanical sweepers, regenerative air (vacuum) sweepers, the Schwarze EV sweeper, and the Netivey Hamifratz "captive hydrology" pavement cleaner. Four separate modeling simulations were made to reflect three to six cleanings each year, periodically spaced from October $1^{\text {st }}$ through March $1^{\text {st }}$ or March $15^{\text {th }}$.

The analysis found that the most effective technology is the Netivey Hamifratz pavement cleaner followed closely by the Schwarze EV and the regenerative air or vacuum sweeper. The least effective cleaner is the mechanical sweeper. However, the most cost effective cleaner is likely the regenerative air or vacuum sweeper. If it is decided to clean the Rosh Ha'ayin segment of the $\mathrm{CIH}$, the selected cleaning equipment, if other than the Netivey Hamifratz $(\mathrm{NH})$ pavement cleaner, should be tested to verify its pick-up performance is equivalent or better than that assumed. In addition, hand cleaning of the gutters along the sections of porous pavement should be conducted in the same manner that occurred when the highway was cleaned during the monitoring period.

\subsubsection{Impact of Cleaning Practices on Chromium Concentrations}

As discussed in Section 8.8.1, it was estimated that approximately $13 \%$ of the storms under a projected 100,000 vehicles per day may exceed the Israeli drinking water standard for chromium (TCr) of $0.05 \mathrm{mg} / \mathrm{L}$. If the objective of a cleaning program on the $\mathrm{CIH}$ was to reduce the chromium loadings so that the Rosh Ha'ayin segment pavement discharges will not exceed the Israeli drinking water standard more than $5 \%$ to $10 \%$ of the time, for example, the needed reduction in the TSS loads could be on the order of $10 \%$ to $30 \%$. A detailed examination focused on the impact these four cleaning practices have on the distribution of chromium concentrations in the CIH pavement discharges. The model simulated the 2037 chromium concentrations that would occur assuming the sixteen alternative cleaning operations (i.e. four cleaning technologies times four different cleaning frequencies) were implemented throughout the $57 \mathrm{y}$ simulation period. Table 8.5 presents a summary of the effect of these sweeping practices on the frequency of chromium exceedances of the Israeli Drinking Water Standards. 
Table 8.5 Effect of cleaning practices on the frequency of compliance with the Israeli $\mathrm{TCr}$ drinking water standard.

\begin{tabular}{lccccc}
\hline & \multicolumn{5}{c}{ Cleaning Frequency } \\
\cline { 2 - 6 } Technology & 0 & 3 & 4 & 5 & 6 \\
\hline Mechanical & $86.7 \%$ & $90.6 \%$ & $92.0 \%$ & $93.0 \%$ & $93.8 \%$ \\
Regenerative air & $86.7 \%$ & $90.6 \%$ & $92.2 \%$ & $93.3 \%$ & $95.0 \%$ \\
Schwarze & $86.7 \%$ & $90.6 \%$ & $92.0 \%$ & $93.3 \%$ & $94.4 \%$ \\
NH & $86.7 \%$ & $91.1 \%$ & $92.8 \%$ & $93.9 \%$ & $95.7 \%$ \\
\hline
\end{tabular}

Loading reductions were estimated from SIMPTM for cleaning practices that resulted in alternative frequencies of compliance with the TCr drinking water standard. Table 8.6 presents the annual load reductions projected to occur using cleaning practices designed to achieve $95 \%$ compliance with the current TCr drinking water standard. Table 8.6 reflects the use of a regenerative air or vacuum sweeper to clean the Rosh Ha'ayin segment six times each wet weather season.

Table 8.6 Average annual pollutant loadings ${ }^{a}$ for $\mathrm{ClH}$ under low $^{\mathrm{b}}$ and high $^{\mathrm{c}}$ traffic volume conditions with $95 \%$ compliance with $\mathrm{TCr}$ drinking water standard.

\begin{tabular}{|c|c|c|c|c|c|c|c|c|}
\hline \multirow[b]{2}{*}{ Pollutant } & \multicolumn{4}{|c|}{ Traditional Pavements } & \multicolumn{4}{|c|}{ Porous Pavements } \\
\hline & $\begin{array}{l}\text { Low } \\
\text { Traffic }\end{array}$ & $\begin{array}{c}\% \\
\text { Reduce }^{\mathrm{d}} \\
\end{array}$ & $\begin{array}{l}\text { High } \\
\text { Traffic }\end{array}$ & $\begin{array}{c}\% \\
\text { Reduce }^{\mathrm{d}}\end{array}$ & $\begin{array}{l}\text { Low } \\
\text { Traffic }\end{array}$ & $\begin{array}{c}\% \\
\text { Reduce }^{\mathrm{d}}\end{array}$ & $\begin{array}{l}\text { High } \\
\text { Traffic }\end{array}$ & $\begin{array}{c}\% \\
\text { Reduce }^{\mathrm{d}}\end{array}$ \\
\hline TSS & 295 & 38 & 1291 & 33 & 369 & 31 & 1300 & 37 \\
\hline $\mathrm{TCr}$ & $\begin{array}{c}.009 \\
1\end{array}$ & 35 & .0413 & 31 & .0144 & 30 & .0485 & 37 \\
\hline $\mathrm{TCu}$ & $\begin{array}{c}.006 \\
8\end{array}$ & 35 & .0307 & 30 & .0104 & 29 & .0332 & 37 \\
\hline $\mathrm{TPb}$ & $\begin{array}{c}.030 \\
8\end{array}$ & 35 & .139 & 31 & .0477 & 29 & .180 & 35 \\
\hline $\mathrm{TZn}$ & $\begin{array}{c}.031 \\
0\end{array}$ & 34 & .139 & 29 & .0466 & 28 & .176 & 34 \\
\hline $\mathrm{TN}$ & .984 & 39 & 4.27 & 34 & 1.14 & 32 & 3.89 & 38 \\
\hline ТР & .172 & 37 & .765 & 32 & .242 & 30 & .885 & 36 \\
\hline $\mathrm{kg}$ & $\mathrm{b}-\mathrm{km}$ & & & & & & & \\
\hline $\begin{array}{l}\text { Low } \\
\text { Higl } \\
\text { Red }\end{array}$ & $\begin{array}{l}\text { Traffic } \\
\text { Traffic } \\
\text { uction fr }\end{array}$ & $\begin{array}{l}\text { is approx } \\
\text { is appro } \\
\text { om not } \mathrm{c}\end{array}$ & $\begin{array}{l}\text { ately } 10 \\
\text { ately } 1 \\
\text { hed loac }\end{array}$ & $\begin{array}{l}00 \text { vehic } \\
000 \text { vehi } \\
\text { ggs }\end{array}$ & $\begin{array}{l}\text { per day } \\
\text { es per d. }\end{array}$ & & & \\
\hline
\end{tabular}




\subsection{Conclusions}

The review of the monitoring data and model simulation with SIMPTM leads to the following conclusions.

1. The quality of stormwater, and the accumulation of road dirt and its chemistry observed on the $\mathrm{CIH}$ is typical of the stormwater quality observed from freeways in other countries with similar traffic volumes.

2. Dry weather road dirt accumulations on porous pavements for existing high traffic highways were found to be much greater than those for traditional impervious asphalt pavements. This was attributed to the unique design of the highway that results in a $30 \mathrm{~cm}$ wide and 50 $\mathrm{mm}$ deep gutter channel located between the New Jersey barrier and the porous pavement lift that efficiently traps windblown road dirt.

3. Annual pollutant loadings simulated for porous pavement runoff were slightly greater than those for traditional impervious asphalt pavements. This was largely attributed to the greater road dirt accumulations (see conclusion no. 2 above) but also to greater runoff velocities due to the constricted flow in the $50 \mathrm{~mm}$ deep gutter channel that existed where porous pavement was used.

4. It is estimated that without pavement cleaning, the quality of the stormwater washed from either type of pavement will over the long term comply with the Israeli Drinking Water Standards for $87 \%$ of all storms, but $0 \%$ with respect to the draft Kishon River standards.

5. Currently, the observed quality of water in the Einat and Rosh Ha'ayin channels above the CIH fails to meet either the drinking water or draft river standards at similar frequencies to the stormwater from the $\mathrm{CIH}$.

6. Compliance of the stormwater from the $\mathrm{CIH}$ with the drinking water standards can be increased from $87 \%$ to $90 \%$ by cleaning the Rosh Ha'ayin segment three times per year during the wet season; and $95 \%$ if cleaned six times per wet season each year. 
7. Because the Rosh Ha'ayin segment's pavement represents only $1 \%$ of the watershed area draining to the two channels, cleaning the $\mathrm{CIH}$ by itself will not provide noticeable water quality benefits.

8. The containment basins and other practices by CIHC and Derech Eretz Construction Joint Venture provide satisfactory prevention of the potential harmful effects of hazardous chemical spills from accidents on the $\mathrm{CIH}$.

\subsection{Recommendations}

Lacking a national or watershed policy that leads to the reduction of nonpoint pollution from all sources in the watershed of the Einat and Rosh Ha'ayin channels, it is recommended that the Rosh Ha'ayin segment of the $\mathrm{CIH}$ not be cleaned or swept at this time.

If it is decided to clean the Rosh Ha'ayin section of the $\mathrm{CIH}$, the selected cleaning equipment, if other than the Netivey Hamifratz $(\mathrm{NH})$ pavement cleaner, should be tested to verify its performance. In addition, hand cleaning of the gutters along the sections of porous pavement should be conducted in the same manner that occurred when the highway was cleaned during the monitoring period.

To verify the simulations of SIMPTM, it is recommended that the CIH Ltd conduct further monitoring when the traffic volume reaches approximately 100,000 vehicles per day. The types of data collected should be specific to the needs of verifying the model simulations. The detailed monitoring plan should be prepared when the volume of traffic approaches 100,000 vehicles.

Current measures to protect against the potential harmful effects of accidental hazardous chemical spills should be continued.

\section{References}

Drapper, D., R. Tomlinson, and P. Williams, 2000. Pollutant Concentrations in Road Runoff: Southeast Queensland Case Study, J. Env. Eng., 126, 4, 313.

Driscoll, E.D., P.E. Shelley, and E. Strecker, 1990. Pollutant Loadings and Impacts from

Highway Stormwater Runoff, Volume 3, Analytical Investigation and Research Report, FHWA-RD-88-008. 
Hoffman, E.J., J.S. Latimer, C.D. Hunt, G.L. Mills, and J.G. Quinn, 1985. Stormwater Runoff from Highways, Water, Air, and Soil Pollution, 25, 349. 23, 4.

Horner, R.R., and B.W. Mar, 1984. Guide for Water Quality Impact Assessment of Highway Operations and Maintenance, Report No. 14, Washington State Department of Transportation (WSDOT).

Irish, L.B., et al., 1998. Use of Regression Models for Analyzing Highway Storm-Water Loads, J. Env. Eng., 124, 10, 987.

Kobriger, N.P., 1981. Constituents of Highway Runoff, FHWA/RD-81-044.

Shaheen, D.G., 1975. Contributions of Urban Roadway Usage to Water Pollution, U.S. Environmental Protection Agency, EPA-600/2-75-004.

Shirley, E.C., et al., 1982. Estimating Highway Runoff Quality, California Department of Transportation.

Sutherland, R. and S.L. Jelen. 1997. "Contrary to Conventional Wisdom, Street Sweeping Can be an Effective BMP." Journal of Water Management Modeling R195-09. doi: 10.14796/JWMM.R195-09.

Sutherland R.C., and S.L. Jelen, 1998. Simplified Particulate Transport Model User's Manual, Version 3.2, Pacific Water Resources, Inc., Beaverton, Oregon.

Sutherland, R. and S.L. Jelen. 2002. "Stormwater Quality Modeling Improvements Needed for SWMM." Journal of Water Management Modeling R215-13. doi: 10.14796/JWMM.R215-13.

Thomson, N.R., E.A. McBean, W. Snodgrass, and I.B. Monstrenko, 1997. Highway Stormwater Runoff Quality: Development of Surrogate Parameter Relationships, Water, Air and Soil Pollution, 94, 307.

Wu, J. S., et al, 1998. Characterization and Pollutant Loading Estimation for Highway Runoff, J. Env. Eng., 124, 7, 584. 